\title{
APLIKASI BIMBINGAN PRAKTEK KERJA LAPANGAN (PKL) DAN SKRIPSI BERBASIS WEB
}

\author{
Andie $^{1)}$ \\ ${ }^{1}$ Fakultas Teknologi Informasi, Universitas Islam Kalimantan Muhammad Arsyad Al Banjari Banjarmasin \\ Email : andina777@gmail.com
}

\begin{abstract}
Abstrack
Proses bimbingan Praktek Kerja Lapangan (PKL) dan Skripsi di Fakultas Teknologi Informasi (FTI) Universitas Islam Kalimantan Muhammad Arsyad Al Banjari Banjarmasin memiliki beberapa kendala yang menyebabkan proses pengerjaan PKL dan Skripsi mahasiswa terhambat, yaitu dokumentasi judul skripsi yang kurang tertata, batas waktu bimbingan yang singkat dan kesulitan mahasiswa dan dosen untuk mengadakan pertemuan. Untuk mengatasi permasalahan tersebut, perlu dirancang sistem pendukung bimbingan PKL dan Skripsi dengan menerapkan teknologi aplikasi sehingga dapat bekerja layaknya bimbingan skripsi secara tatap muka.

Sistem yang dirancang dalam penelitian ini dibuat dalam ruang lingkup UNISKA berdasarkan informasi dan prosedur pembuatan PKL dan Skripsi Fakultas Teknologi Informasi (FTI) yang dapat dilakukan secara online dan dirancang menggunakan model Waterfall. Aplikasi dirancang dengan bahasa pemrogramam PHP dibantu dengan Javascript dan CSS, dan Database Management System (DBMS) MySQL.
\end{abstract}

Kata kunci: aplikasi, PKL, skripsi, web

\section{PENDAHULUAN}

Saat ini perkembangan teknologi sangat pesat dan peranannya sangat penting untuk mendukung aktivitas manusia agar dapat mengoptimalkan waktu dengan lebih baik. Salah satu contoh teknologi yang membantu aktivitas manusia adalah aplikasi. Instansi yang bergerak di bidang pendidikan seperti Universitas juga membutuhkan dukungan aplikasi dalam peningkatan mutu pelayanan terhadap proses pendidikan, seperti sistem informasi akademik yang terdiri dari banyak proses antara lain perencanaan perkuliahan hingga proses akhir seperti bimbingan skripsi.

Tugas akhir atau skripsi adalah karya tulis ilmiah mahasiswa, yang merupakan kulminasi proses berpikir ilmiah sesuai dengan disiplin ilmunya, yang disusun untuk memenuhi persyaratan memperoleh gelar sesuai dengan jenjangnya. (Andie, Firdaus, \& Hasanuddin, 2019) Di Fakultas Teknologi Informasi (FTI) Universitas Islam Kalimantan (UNISKA) Muhammad Arsyad Al-Banjari Banjarmasin, mahasiswa yang ingin mengajukan proposal skripsi harus mencari informasi skripsi yang sudah ada terutama skripsi yang membahas masalah yang serupa dengan masalah yang ingin diangkat oleh mahasiswa yang ingin mengajukan skripsi. Kemudian, mahasiswa yang proposal skripsinya disetujui oleh Ketua Program Studi, dapat memulai proses bimbingan skripsi. Dalam prakteknya, aktivitas bimbingan tugas akhir di FTI UNISKA dilakukan dengan diskusi, tanya jawab, dan pemberian masukan melalui tatap muka antar mahasiswa dan dosen pembimbing.

Dalam proses bimbingan PKL dan Skripsi di FTI UNISKA, terdapat beberapa kendala yang menyebabkan proses pengerjaan PKL dan SKRIPSI mahasiswa terhambat. Kendalakendala tersebut antara lain sebagai berikut:

1. Dokumentasi judul skripsi yang sudah digunakan kurang tertata bahkan tidak terdata secara benar, sehingga mahasiswa harus mencari judul skripsi yang sudah digunakan satu persatu di perpustakaan Universitas agar tidak menggunakan judul yang sama.

2. Kesulitan mahasiswa dan dosen untuk mengadakan pertemuan dalam rangka bimbingan PKL dan Skripsi dikarenakan perbedaan jadwal kesibukan masing-masing individu. 
3. Banyaknya keterlambatan bimbingan mahasiswa karena setiap dosen tidak dapat mengontrol waktu bimbingan, begitu pula dengan mahasiswa tidak dapat mengetahui sudah sampai mana progres bimbingannya.

Untuk mengatasi permasalahan tersebut, perlu dirancang aplikasi pendukung bimbingan PKL dan Skripsi, yang dapat membantu menyelesaikan permasalahan yang dihadapi dalam proses bimbingan PKL dan Skripsi di FTI UNISKA saat ini dengan menerapkan teknologi informasi sehingga dapat bekerja layaknya bimbingan skripsi secara tatap muka dengan perantara sistem. Berdasarkan hal-hal tersebut, munculah gagasan untuk membuat Aplikasi Bimbingan PKL dan Skripsi online untuk mahasiswa. Aplikasi ini diharapkan akan memberikan kemudahan baik bagi para mahasiswa maupun dosen pembimbing untuk melakukan bimbingan skripsi sehingga dapat meminimalisir proses pembuatan PKL dan Skripsi akibat perbedaan jadwal kesibukan antara mahasiswa dan dosen pembimbing.

\section{METODE PENELITIAN}

Untuk memperoleh data yang diperlukan dalam penyusunan penelitian ini dengan menggunakan metode pengumpulan data sebagai berikut:

1. Wawancara atau interview

Wawancara adalah suatu metode yang digunakan untuk memperoleh data dengan cara mengajukan pertanyaan-pertanyaan secara langsung.

2. Pengamatan Langsung atau Observasi.

Observasi adalah metode pengumpulan data dengan cara mengamati secara langsung proses pendataan data tracer study.

3. Studi Pustaka

Studi pustaka adalah suatu metode pengumpulan data dengan menggunakan buku-buku dan pencarian di internet sebagai bahan referensi dalam penulisan laporan dan pembuatan sistem.

Dalam pengembangan sistem ini, ada beberapa tahapan yang harus dilakukan. Adapun tahapan tersebut adalah sebagai berikut:

\section{Analisa Sistem}

Dalam membangun aplikasi ini diperlukan perencanaan yang baik agar dihasilkan sistem yang dapat berjalan optimal. Tahap perencanaan ini terbagi atas 2 yaitu:

1. Menentukan tujuan pembuatan aplikasi

Tujuan penelitian ini adalah agar mempermudah petugas pengumpulkan data dan pencarian data alumi berupa tracer study di Universitas Islam Kalimantan (UNISKA) Muhammad Arsyad Al-Banjari Banjarmasin

2. Menentukan siapa yang akan menjadi pemakai

Sistem informasi website tracer study ini bisa digunakan oleh alumni sebagai pemakai dan administrator website sebagai pengelola data.

\section{Perancangan Sistem}

Proses perancangan yang baik diperlukan untuk pembuatan program tak terkecuali dalam pembuatan aplikasi yang baik. Perancangan sistem secara terperinci, dilakukan dengan cara:
a. Rancangan Menu
b. Rancangan Database
c. Relasi Antar Tabel
d. Diagram Konteks
e. Data Flow Diagram (DFD)
f. Rancangan Tampilan
g. Rancangan Output dan Laporan
h. Pembuatan Program

Pembuatan Aplikasi bimbingan PKL dan Skripsi ini dibuat menggunakan bahasa pemrograman PHP dan MySQL sebagai pengelola databasenya. (Peranginangin \& Kasiman, 2006)

\section{Testing Aplikasi}

Pada tahap ini, dilakukan uji terhadap sistem yang telah selesai dibuat dengan menggunakan modem dan satu buah laptop server, setiap proses pendaftaran dan perubahan status data tracer study diuji baik dari segi pengguna, pemakai maupun pengelola.

\section{HASIL DAN PEMBAHASAN}

Pada bab ini, semua rancangan penelitian akan diimplementasikan ke sebuah aplikasi jadi berdasarkan tahapan penelitian sebagai berikut:

\section{a. Daftar Menu}

Semua menu yang akan dibuat di aplikasi harus di rancang terlebih dahulu sesuai yang dikehendaki. Berikut daftar menu untuk aplikasi bimbingan praktek kerja lapangan (PKL) dan skripsi: 
Tabel 1. Daftar Menu

\begin{tabular}{|c|c|c|}
\hline Level User & Menu & Submenu \\
\hline \multirow[t]{6}{*}{ Mahasiswa } & Login & \\
\hline & Home & \\
\hline & $\begin{array}{l}\text { List } \\
\text { Pembimbing }\end{array}$ & \\
\hline & Kirim Pesan & \\
\hline & Akunku & \\
\hline & Logout & \\
\hline \multirow[t]{7}{*}{ Dosen } & Login & \\
\hline & Home & \\
\hline & $\begin{array}{l}\text { Input } \\
\text { Mahasiswa }\end{array}$ & \\
\hline & Bimbingan & \\
\hline & Inbox & \\
\hline & Akunku & \\
\hline & Logout & \\
\hline \multirow[t]{10}{*}{ Admin } & Login & \\
\hline & Home & \\
\hline & Data Dosen & \\
\hline & $\begin{array}{l}\text { Dosen <-> } \\
\text { Mahasiswa }\end{array}$ & \\
\hline & $\begin{array}{l}\text { Data } \\
\text { Bimbingan }\end{array}$ & \\
\hline & Percakapan & \\
\hline & Akunku & \\
\hline & Data-Data & Aplikasi \\
\hline & & Kelas \\
\hline & Logout & \\
\hline
\end{tabular}

\section{b. Database}

Database merupakan hal yang utama dalam pembuatan aplikasi berbasis data, database yang dibuat diberi nama fti2018. Berikut tabel-tabel yang dibuat pada aplikasi bimbingan praktek kerja lapangan (PKL) dan skripsi: (Subekti, 1997) a. Tabel ab_admin

Tabel 2. Tabel ab_admin

\begin{tabular}{|l|l|l|}
\multicolumn{1}{c|}{ Field } & \multicolumn{1}{c|}{ Type } & \multicolumn{1}{c|}{ Ket } \\
\hline id & $\operatorname{int}(11)$ & $\begin{array}{l}\text { Primary Key } \\
\text { \& Auto } \\
\text { Increamen }\end{array}$ \\
\hline nm_admin & varchar(150) & \\
\hline telpon & varchar(15) & \\
\hline email & varchar(150) & \\
\hline password & varchar(100) & \\
\hline
\end{tabular}

b. Tabel ab_aplikasi

Tabel 3. Tabel ab_aplikasi

\begin{tabular}{|l|l|l|}
\hline \multicolumn{1}{|c|}{ Field } & \multicolumn{1}{|c|}{ Type } & \multicolumn{1}{c|}{ Ket } \\
\hline id & $\operatorname{int}(11)$ & $\begin{array}{l}\text { Primary Key \& } \\
\text { Auto Increamen }\end{array}$ \\
\hline aplikasi & varchar(50) & \\
\hline
\end{tabular}

c. Tabel ab_bimbingan

Tabel 4. Tabel ab_bimbingan

\begin{tabular}{|l|l|l|}
\multicolumn{1}{|c|}{ Field } & \multicolumn{1}{c|}{ Type } & \multicolumn{1}{c|}{ Ket } \\
\hline id & int(11) & $\begin{array}{l}\text { Primary } \\
\text { Key \& } \\
\text { Auto } \\
\text { Increamen }\end{array}$ \\
\hline id_mhs & int(11) & \\
\hline nm_mhs & varchar(150) & \\
\hline npm & varchar(8) & \\
\hline id_dsn & int(11) & \\
\hline nm_dosen & varchar(150) & \\
\hline pembimbingke & int(11) & \\
\hline catatan & text & \\
\hline progres & int(11) & \\
\hline waktu & varchar(50) & \\
\hline
\end{tabular}

d. Tabel ab_dosen

Tabel 5. Tabel ab_dosen

\begin{tabular}{|l|l|l|}
\multicolumn{1}{|c|}{ Field } & \multicolumn{1}{c|}{ Type } & \multicolumn{1}{c|}{ Ket } \\
\hline id & int(11) & $\begin{array}{l}\text { Primary Key \& } \\
\text { Auto Increamen }\end{array}$ \\
\hline nm_dosen & varchar(150) & \\
\hline nik & varchar(20) & NULL \\
\hline nip & varchar(20) & NULL \\
\hline nidn & varchar(20) & \\
\hline telpon & varchar(15) & \\
\hline email & varchar(150) & \\
\hline ket & text & NULL \\
\hline
\end{tabular}




\begin{tabular}{|l|l|l|}
\hline password & varchar(100) & \\
\hline waktu & varchar(50) & \\
\hline
\end{tabular}

e. Tabel ab_jenis

Tabel 6. Tabel ab_jenis

\begin{tabular}{|l|l|l|}
\hline \multicolumn{1}{|c|}{ Field } & \multicolumn{1}{|c|}{ Type } & \multicolumn{1}{c|}{ Ket } \\
\hline id & int(11) & $\begin{array}{l}\text { Primary Key \& Auto } \\
\text { Increamen }\end{array}$ \\
\hline jenis & varchar(10) & \\
\hline
\end{tabular}

f. Tabel ab_kelas

Tabel 7. Tabel ab_kelas

\begin{tabular}{|l|l|l|}
\hline \multicolumn{1}{|c|}{ Field } & \multicolumn{1}{|c|}{ Type } & \multicolumn{1}{c|}{ Ket } \\
\hline id & int(11) & $\begin{array}{l}\text { Primary Key \& Auto } \\
\text { Increamen }\end{array}$ \\
\hline kelas & varchar(20) & \\
\hline
\end{tabular}

g. Tabel ab_mhs

Tabel 8. Tabel ab_mhs

\begin{tabular}{|l|l|l|}
\multicolumn{1}{|c|}{ Field } & \multicolumn{1}{c|}{ Type } & \multicolumn{1}{c|}{ Ket } \\
\hline id & int(11) & $\begin{array}{l}\text { Primary Key } \\
\text { \& Auto } \\
\text { Increamen }\end{array}$ \\
\hline jenis & varchar(10) & \\
\hline nm_mhs & varchar(100) & \\
\hline npm & varchar(8) & \\
\hline telpon & varchar(15) & \\
\hline email & varchar(150) & \\
\hline judul & text & \\
\hline aplikasi & varchar(100) & \\
\hline kelas & varchar(20) & \\
\hline status & varchar(15) & \\
\hline password & varchar(100) & \\
\hline waktu & varchar(50) & \\
\hline
\end{tabular}

h. Tabel $a b \_m h s \_b n g$

Tabel 9. Tabel ab_mhs_bng

\begin{tabular}{|l|l|l|}
\multicolumn{1}{c|}{ Field } & \multicolumn{1}{c|}{ Type } & \multicolumn{1}{c|}{ Ket } \\
\hline id & int(11) & $\begin{array}{l}\text { Primary Key \& } \\
\text { Auto Increamen }\end{array}$ \\
\hline id_mhs & $\operatorname{int}(11)$ & \\
\hline nm_mhs & $\operatorname{varchar}(150)$ & \\
\hline npm & $\operatorname{varchar}(8)$ & \\
\hline id_dsn & int(11) & \\
\hline nm_dosen & varchar(150) & \\
\hline jenis & varchar(10) & \\
\hline
\end{tabular}

\begin{tabular}{|l|l|l|}
\hline waktu & varchar(50) & \\
\hline
\end{tabular}

i. Tabel ab_pesan

Tabel 10. Tabel ab_pesan

\begin{tabular}{|c|c|c|}
\hline Field & Type & Ket \\
\hline id & $\operatorname{int}(11)$ & $\begin{array}{l}\text { Primary Key } \\
\text { \& Auto } \\
\text { Increamen }\end{array}$ \\
\hline id_mhs & $\operatorname{int}(11)$ & \\
\hline $\mathrm{nm} \_\mathrm{mhs}$ & varchar(150) & \\
\hline npm & $\operatorname{varchar}(8)$ & \\
\hline email_mhs & varchar(150) & \\
\hline id_dsn & $\operatorname{int}(11)$ & \\
\hline nm_dosen & varchar(150) & \\
\hline email_dsn & $\operatorname{varchar}(150)$ & \\
\hline pesan & text & \\
\hline waktu & varchar(50) & \\
\hline
\end{tabular}

j. Tabel ab_status

Tabel 11. Tabel ab_status

\begin{tabular}{|l|l|l|}
\multicolumn{1}{|c|}{ Field } & \multicolumn{1}{|c|}{ Type } & \multicolumn{1}{c|}{ Ket } \\
\hline id & int(11) & $\begin{array}{l}\text { Primary Key \& } \\
\text { Auto Increamen }\end{array}$ \\
\hline status & varchar(20) & \\
\hline
\end{tabular}

\section{c. Relasi Antar Tabel}

Relasi antar tabel digunakan untuk melihat tabel mana saja yang datanya berhubungan satu sama lain, berikut relasi antar tabel yang terbentuk dari database fti2018:

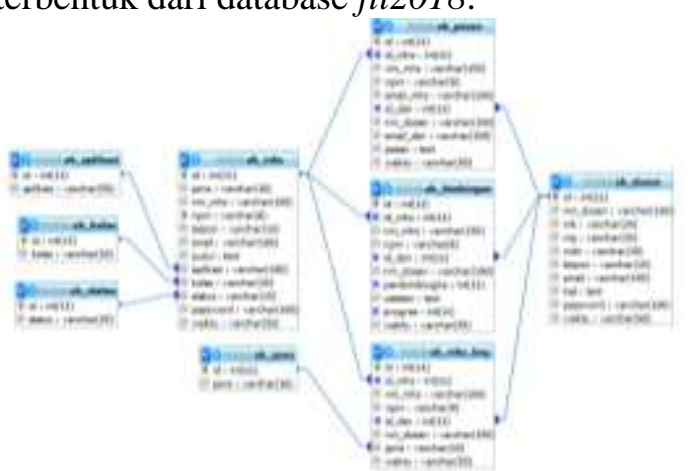

Gambar 1. Relasi Antar Tabel

\section{d. Tampilan Antar Muka}

Tampilan antar muka adalah tampilan yang sudah jadi dari aplikasi yang dibuat, template aplikasi menggunakan Bootstrap, yaitu template AdminLTE. (Rasyidan, Andie, \& Firdaus, 2016) Aplikasi Bimbingan Praktek 
Kerja Lapangan (PKL) dan Skripsi terdiri dari 3 halaman utama atau biasa disebut level admin, yaitu Halaman Mahasiswa, Halaman Dosen, dan Halaman Admin. Berikut tampilan dari masing-masing halaman:

1) Halaman Mahasiswa

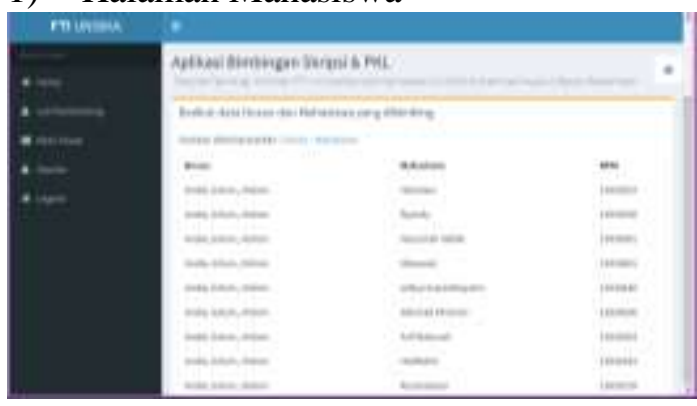

Gambar 2. List Pembimbing Halaman Mahasiswa

2) Halaman Dosen

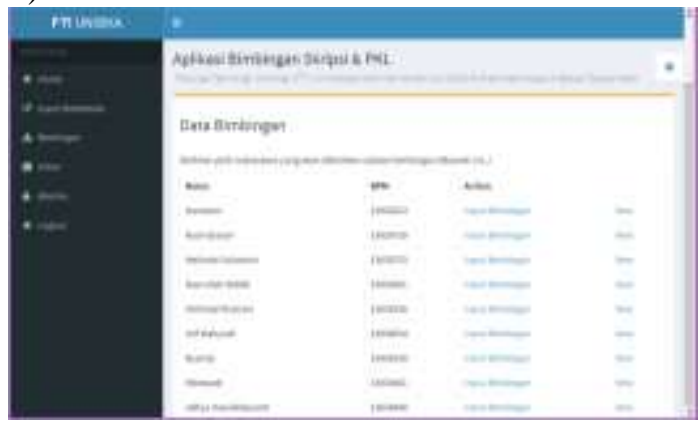

Gambar 3. Data Bimbingan Halaman Dosen

3) Halaman Admin

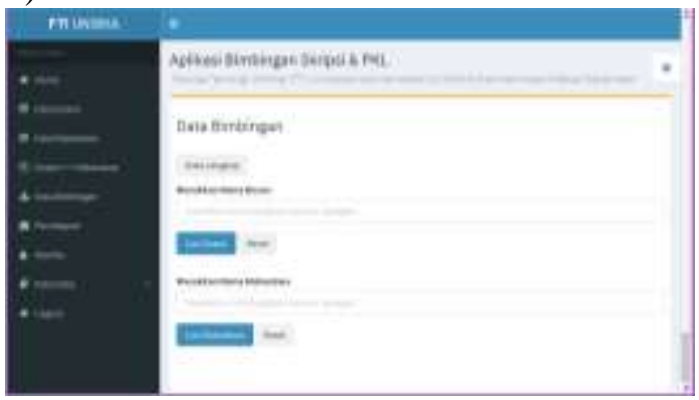

Gambar 4. Data Bimbingan Halaman Admin

\section{e. Output dan Laporan}

Halaman output dan laporan adalah halaman yang dapat di print oleh admin, berikut tampilan dari masing-masing halaman laporan:

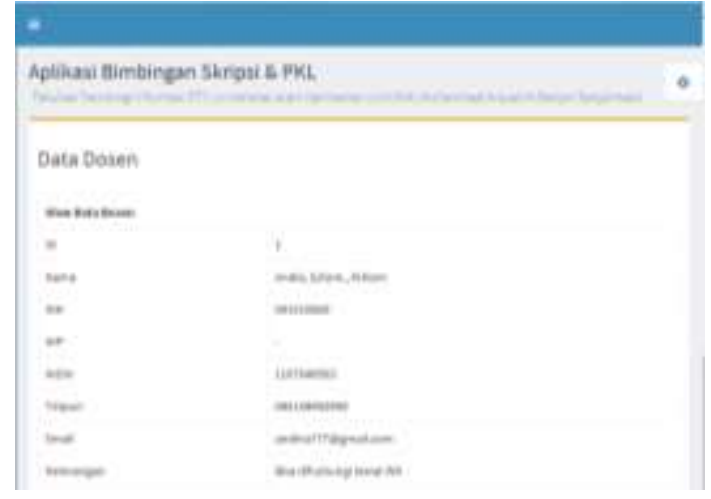

Gambar 5. Laporan Data Dosen

\section{KESIMPULAN}

Aplikasi Bimbingan Praktek Kerja Lapangan (PKL) dan Skripsi adalah aplikasi yang dirancang khusus untuk mencatat data bimbingan dosen agar bisa di pantau oleh Kaprodi atau Dekan. Tujuan penelitian ini adalah agar memberikan kemudahan baik bagi para mahasiswa maupun dosen pembimbing untuk melakukan bimbingan PKL dan skripsi sehingga dapat meminimalisir proses keterlambatan bimbingan PKL dan Skripsi akibat perbedaan jadwal kesibukan antara mahasiswa dan dosen pembimbing.

Objek penelitian dilakukan di Fakultas Teknologi Informasi (FTI) Universitas Islam Kalimantan (UNISKA) Muhammad Arsyad AlBanjari Banjarmasin. Pembuatan aplikasi bimbingan PKL dan Skrisi ini dibuat menggunakan bahasa pemrograman PHP dan MySQL sebagai pengelola databasenya.

Setelah dijalankan selama satu semester, mahasiswa maupun dosen sangat lancar menggunakan aplikasi, karena aplikasi dibuat secara ringkas dan langsung dapat dimengerti cara penggunaan aplikasinya.

\section{REFERENSI}

Andie, Firdaus, M. I., \& Hasanuddin. (2019). Sistem Informasi Website Tracer Study di Universitas Islam Kalimantan (UNISKA) Muhammad Arsyad Al Banjari Banjarmasin. Al Ulum Jurnal Sains Dan Teknologi , 4 (2), 28-32.

Peranginangin, \& Kasiman. (2006). Aplikasi $W E B$ dengan PHP dan MySQL. Yogyakarta: ANDI. 
Rasyidan, M., Andie, \& Firdaus, M. I. (2016).

Perancangan Aplikasi Absensi Kelas

Berbasis SMS Gateway. Al Ulum Jurnal

Sains Dan Teknologi , 2 (1), 52-57.

Subekti, M. (1997). Sistem manajemen Basis

Data. Jakarta: Universitas Bina Nusantara. 